\title{
Purification and characterization of guinea-pig chorionic gonadotrophin*
}

\author{
C. S. Bambra†, S. S. Lynch $\ddagger$, G. R. Foxcroft, G. Robinson $\S$ \\ and E. C. Amoroso
}

A.R.C. Research Group on Hormones and Farm Animal Reproduction, University of Nottingham Faculty of Agricultural Science, Sutton Bonington, Loughborough LE12 SRD; $\$$ Department of

Clinical Endocrinology, Birmingham and Midland Hospital for Women, Showell Green Lane, Sparkhill, Birmingham B11 4HL; and \$Department of Histopathology, University Hospital, Queen's Medical Centre, Nottingham NG7 2UG, U.K.

\begin{abstract}
Summary. A human chorionic gonadotrophin-like protein (GF-1, 1.0 g) from the placentae of 50 guinea-pigs killed at Day 26 of gestation was purified by $\mathrm{pH}$ and ammonium salt fractionation followed by column chromatography on DEAESephadex and filtration on Sephadex G-100. Relative to the Second International hCG standard (MRC 61/6) GF-l had an immunological potency of 21000 i.u./mg as measured in a specific hCG- $\beta$ radioimmunoassay and, using the ovarian ascorbic acid depletion assay, an apparent biological potency of $24064 \mathrm{i} . \mathrm{u} . / \mathrm{mg}$. Isoelectric focussing yielded 6 bands between $\mathrm{pH} 4.4$ and 5.7 and the material comprised two non-covalently linked subunits. The Stokes' radii were $3.40 \mathrm{~nm}$ for the native preparation, and $2.38 \mathrm{~nm}$ and $3 \cdot 15 \mathrm{~nm}$ for GF-1- $\alpha$ and GF-1- $\beta$ subunits respectively. The guinea-pig placenta therefore produces a chorionic gonadotrophin which on purification has physicochemical, biological and immunological properties similar to those of hCG.
\end{abstract}

\section{Introduction}

The presence of placental gonadotrophins is well documented for primates (Aschheim \& Zondek, 1927; Hodgen, Tullner, Vaitukaitis, Ward \& Ross, 1974; Hobson \& Wide, 1976) and equids (Cole \& Hart, 1930; Allen, 1979) but chorionic gonadotrophin (CG)-like proteins have been reported for few other animals. Biologically active gonadotrophins with gonadotrophin profiles similar to hCG and its subunits are present in the placentae of the rat, mouse and hamster (Wide \& Hobson, 1978), and implanting mouse blastocysts synthesize and release a glycoprotein allied to chorionic gonadotrophin (Fishel \& Surani, 1980). These CG-like proteins have also been reported in the rock hyrax and spring-hare (Gombe, Oduor-Okelo \& Else, 1980). Bambra (1981), using an immuno-histochemical technique involving a specific antiserum against the hCG- $\beta$ subunit, has demonstrated the presence of an hCG-like material in the guinea-pig placenta on Days 16, 21, 31 and 46 of pregnancy and electron microscope studies suggest that this material is probably synthesized in the spongy syncytium.

The studies described in this paper were carried out in an attempt to extract, purify and characterize this hCG-like material present in the guinea-pig placenta.

\footnotetext{
* Reprint requests to: Dr G. R. Foxcroft.

$\dagger$ Present address: Institute of Primate Research, P.O. Box 114, Limuru, Kenya.

II Deceased.
} 


\section{Materials and Methods}

For use in the ovarian ascorbic acid depletion assay hCG (Primogonyl) and PMSG (Anteron) were purchased from Schering Ag (Berlin, West Germany). Blue dextran, cytochrome-C, chymotrypsinogen, ovalbumin and bovine serum albumin, DEAE-Sephadex A50 and A25 and Sephadex G-100 and G-150 were products of Pharmacia Fine Chemicals (Uppsala, Sweden). Cellogel was purchased from Lab. Sales Ltd (U.S.A.), and Coomassie brilliant blue R250 was a product of Colab Lab. (Chicago, U.S.A.).

Extraction and fractionation of placentae. Placentae were collected from 50 guinea-pigs at Day 26 of gestation. A crude placental extract was prepared by a modification of the method of Lee, Wong, Lee \& $\mathrm{Ma}$ (1977) in which the $\mathrm{pH}$ of the homogenate was adjusted with $\mathrm{HCl}$ to $5 \cdot 3$ and $4 \cdot 3$ instead of $\mathrm{pH} 4.0$ and 3.0 respectively.

Purification of hCG-like material. All steps of purification were carried out according to the method of Bahl (1969) and were done at $4^{\circ} \mathrm{C}$ unless specified otherwise. Eluates from columns were monitored for protein content by measuring absorbance at $280 \mathrm{~nm}$. Pooled peaks were assayed for hCG-like activity using radioimmunoassay.

Radioimmunoassay. An hCG- $\beta$ subunit double-antibody radioimmunoassay was used to monitor column eluates for hCG-like activity. The rabbit antiserum used (F98) was produced with a multisite intradermal injection technique against the hCG- $\beta$ subunit preparation CR115 (R. E. Canfield, New York). This antiserum was used at a final dilution of 1:125000 and showed crossreactivity with other human protein hormones as follows: CG, $6.67 \%$; CG- $\alpha,<0.2 \%$; FSH, $0.2 \%$; FSH- $\alpha, 0.27 \%$; FSH- $\beta,<0.2 \%$; LH, $5.0 \%$; LH- $\alpha, 0.36 \%$; LH- $\beta, 0.8 \%$; TSH, $1.0 \% ;$ GH, $<0.2 \%$; placental lactogen, $<0.2 \%$; prolactin, $<0.2 \%$. The hCG- $\beta$ subunit preparation CR 115 was used for iodination and, after demonstrating parallelism to inhibition curves obtained with the purified hCG- $\beta$ preparation CR1 15, the Second International hCG Standard (MRC 61/6, NIBSC, London) was used as the reference material. Serial dilutions of human pregnancy serum, guinea-pig plasma at mid-pregnancy and placental extracts from the guinea-pig showed no significant deviation from parallelism to the hCG- $\beta$ standard curves: the assay sensitivity was $<0 \cdot 12 \mathrm{mi}$.u./tube. The interassay coefficient of variation was $5 \cdot 1 \%$.

Isoelectric focussing on cellulose acetate membranes. This was performed according to the method of Ambler \& Walker (1979) using an ampholyte gradient of pH 3.5-10. Proteins focussing at different $\mathrm{pH}$ points were eluted with $0.9 \%(\mathrm{w} / \mathrm{v}) \mathrm{NaCl}$ and assayed for hCG-like activity.

Bioassay. Biological activity was estimated using a modification of the ovarian ascorbic acid depletion assay as described by Parlow (1961). A four-point design was used and the Second International hCG Standard was used as the reference preparation. The relative potency, fiducial limits of error at $P=0.95$ and index of precision $(\lambda)$ of each assay were calculated according to the method of Gaddum (1953).

Separation of subunits. The separation of the subunits of the purified guinea-pig hCG-like protein (GF-1) was carried out according to the method of Morgan \& Canfield (1971).

Stokes' radius and approximate molecular weight determinations. The Stokes' radius and approximate molecular weight determinations were carried out by gel filtration on Sephadex G-150 according to the method of Ryan, Jiang \& Hanlon (1970). A solution of $5 \mathrm{ml}$ containing $15 \mathrm{mg}$ of each of (1) cytochrome-C $\left(M_{r} 12500\right.$, Stokes' radius $\left.1.64 \mathrm{~nm}\right)$, (2) bovine serum albumin $\left(M_{r}\right.$ $67000,3.55 \mathrm{~nm})$, (3) ovalbumin $\left(M_{r} 43000,3.05 \mathrm{~nm}\right)$ and (4) chymotrypsinogen $A\left(M_{r} 25000,2.09\right.$ $\mathrm{nm})$ was applied to a column of Sephadex G-150 $(2 \times 100 \mathrm{~cm})$ previously equilibrated with $0.04 \mathrm{M}$ sodium phosphate buffer, pH 7.5 at $4^{\circ} \mathrm{C}$. Samples $(10 \mathrm{mg})$ of native GF-1, GF- $1 \alpha$ and GF- $1 \beta$ in $5 \mathrm{ml}$ buffer were each chromatographed separately on the same column under identical conditions. 
Gel electrophoresis. The separation was performed using $7 \%$ cross-linked polyacrylamide gels with a running pH of 6.8 at $30 \mathrm{~mA}$ for $12 \mathrm{~h}$ according to the method of Swank \& Munkres (1971). Gels were run under reducing ( $8 \mathrm{M}$-urea in gel mixture) and non-reducing conditions.

\section{Results}

\section{Purification}

The use of $\mathrm{pH}$ and ammonium sulphate fractionation yielded $10 \cdot 3 \mathrm{~g}$ of a freeze-dried crude extract (CPE-26) with an immunoassay potency of $7080 \mathrm{i} . \mathrm{u} . / \mathrm{mg}$. Ion exchange chromatography of CPE-26 on a DEAE-Sephadex A50 column yielded several peaks designated I-XI as shown in the elution profile presented in Text-fig. 1. Peaks V to IX showed the presence of hCG-like material by radioimmunoassay. The greatest immunoassay potency was present in pooled peak VIII which yielded $1.8 \mathrm{~g}$ of a freeze-dried material (designated IC-1) with an immunological potency of 12800 i.u./mg.

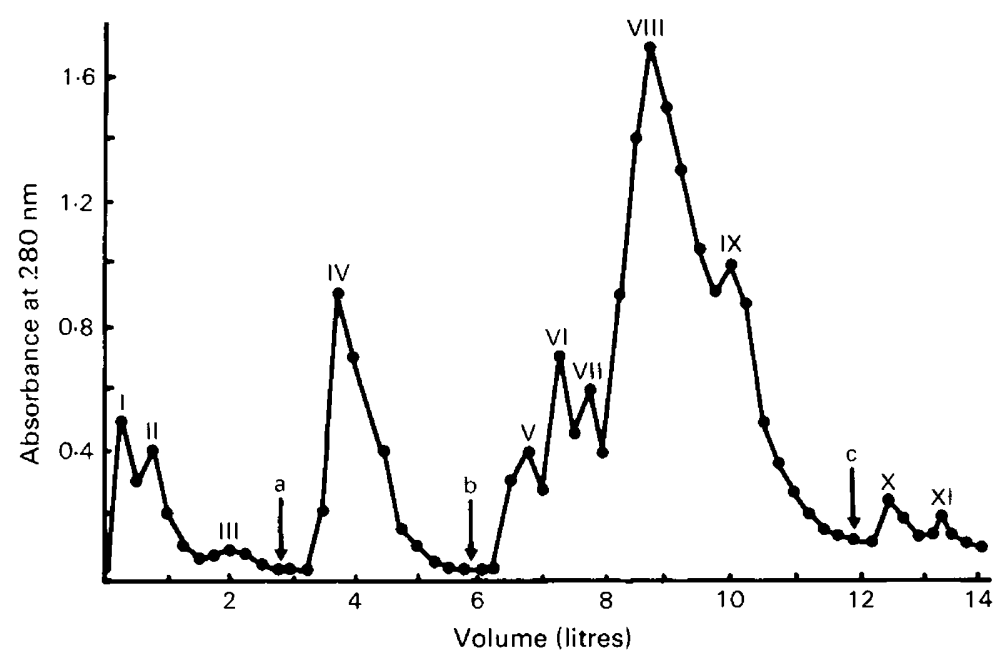

Text-fig. 1. Chromatography of crude guinea-pig material on DEAE-Sephadex 50. Sample in $0.02 \mathrm{M}$-Tris-phosphate buffer, $\mathrm{pH} 8.7$, was applied to the column $(5 \times 100 \mathrm{~cm})$ in $0.04 \mathrm{M}$-Trisphosphate buffer and eluted in a step-wise discontinuous gradient. Elution was started with $0.04 \mathrm{M}$-Tris-phosphate buffer, $\mathrm{pH} 8.7$, and was changed to $0.1 \mathrm{M}-\mathrm{NaCl}$ (a) and $0.2 \mathrm{M}-\mathrm{NaCl}$ (b) in $0.04 \mathrm{M}$-Tris-phosphate buffer, $\mathrm{pH} 8.7$, and finally $0.2 \mathrm{M}-\mathrm{NaCl}$ (c) in $0.04 \mathrm{M}$-Tris-phosphate, $\mathrm{pH}$ 9. Absorbance of every 25 th fraction is shown.

Rechromatography of preparation IC- 1 on a $2.5 \times 100 \mathrm{~cm}$ DEAE-Sephadex A50 column, using a $0 \cdot 1-0 \cdot 2 \mathrm{M}-\mathrm{NaCl}$ linear salt gradient in $400 \mathrm{ml} 40 \mathrm{~mm}$-Tris-phosphate $\mathrm{pH} 8 \cdot 3$, yielded a single large peak. Pooling and freeze-drying of the fractions within this peak gave a yield of $1 \cdot 1 \mathrm{~g}$ of a preparation (designated IC-2) with an immunological potency of 15700 i.u./mg. Preparation IC-2 was subjected to further purification by gel filtration on a $2.5 \times 100 \mathrm{~cm}$ Sephadex G-100 column in $0.05 \mathrm{M}$-sodium phosphate buffer $\mathrm{pH} 7.5$. A highly purified material (designated GF-1) eluted as a single peak and when pooled produced a yield of $1.0 \mathrm{~g}$ of freeze-dried material with an immunoassay potency of 21000 i.u./mg.

An aqueous solution of GF-1 $(1 \mathrm{mg} / \mathrm{ml})$ had an optical density of 0.38 at $280 \mathrm{~nm}$ in a $1-\mathrm{cm}$ cell. 
Isoelectric focussing

Preparation GF-1 focussed in 6 bands between $\mathrm{pH} 4.4$ and 5.7 on a cellulose acetate membrane and after elution each of these bands was immunoactive. The isoelectric focussing points of these bands and their estimated immunological potencies are shown in Table 1 and are compared with data from isoelectric focussing studies of a number of hCG preparations.

Table 1. A comparison of the isoelectric points of a purified guineapig placental extract (GF-1) and different preparations of hCG and the immunological potencies associated with eluates of GF-1 isoelectric bands $1-6$

\begin{tabular}{lcccccc}
\hline & \multicolumn{6}{c}{ Isoelectric band number } \\
\cline { 2 - 7 } & 1 & 2 & 3 & 4 & 5 & 6 \\
\hline (a) Isoelectric points & & & & & & \\
GF-1; this study & $4 \cdot 4$ & $4 \cdot 6$ & $4 \cdot 9$ & $5 \cdot 1$ & $5 \cdot 5$ & $5 \cdot 7$ \\
hCG; Brossmer et al. (1971) & $4 \cdot 0$ & $4 \cdot 2$ & $4 \cdot 5$ & $4 \cdot 6$ & $4 \cdot 9$ & $5 \cdot 2$ \\
hCG; Graesslin et al. (1972) & $3 \cdot 8$ & $4 \cdot 3$ & $4 \cdot 5$ & 4.9 & $5 \cdot 1$ & - \\
hCG; Merz et al. (1974) & $4 \cdot 0$ & $4 \cdot 2$ & $4 \cdot 6$ & $4 \cdot 7$ & $4 \cdot 9$ & $5 \cdot 2$ \\
hCG; Qazi et al. (1974) & & $3 \cdot 73$ & $-4 \cdot 35$ & & & \\
(b) Immunoassay potency & & & & & & \\
GF-1 (i.u./l); this study & 20 & 31 & 59 & 28 & 30 & 8 \\
\hline
\end{tabular}

\section{Bioassay}

A pilot assay showed that 15 and $45 \mathrm{i} . \mathrm{u}$. of the 2 nd International Standard hCG preparation were suitable for use as standard potencies in the four-point ascorbic acid depletion assay. On the basis of its immunological potency, preparation GF-1 was assayed at two dose ranges of $0 \cdot 6,1 \cdot 8$ and $5.4 \mu \mathrm{g}$ and $1 \cdot 1,3.3$ and $9.9 \mu \mathrm{g}$ per rat respectively in separate assays. The index of precision for these assays was 0.11 and 0.9 and the estimates (and $95 \%$ confidence limits) of relative biological potency were 22585 (18 500-27 583) and 25545 (22 454-29 273) respectively, giving a mean biological potency of 24064 i.u./mg.

\section{Separation of subunits}

The elution pattern of $400 \mathrm{mg} \mathrm{GF}-1$ material treated with 10 M-urea, from a $2.5 \times 100 \mathrm{~cm}$ DEAE-Sephadex A25 column is shown in Text-fig. 2. In the hCG- $\beta$ RIA the first emergent peak had a potency of $<30 \mathrm{i} . \mathrm{u} . / \mathrm{mg}$ compared to a potency of $15000 \mathrm{i} . \mathrm{u} . / \mathrm{mg}$ in the second emergent peak and the peaks were therefore tentatively designated as $\alpha$ and $\beta$ subunits. Incubation of the two peaks together for $3 \mathrm{~h}$ at room temperature resulted in $63 \%$ recombination as determined by gel filtration and immunoelectrophoresis.

\section{Stokes' radius and molecular weight}

Gel filtration of GF-1 on Sephadex G-150 gave a value of $3.40 \mathrm{~nm}$ for the Stokes' radius and 59000 for the molecular weight. The $\alpha$-subunit of GF-1 had a Stokes' radius of $2.38 \mathrm{~nm}$ and a molecular weight of 30500 . The corresponding values for the $\beta$-subunit of GF-1 were $3 \cdot 15 \mathrm{~nm}$ and 49000 . 


\section{PLATE 1}


Polyacrylamide gel electrophoresis of A, crude guinea-pig material; B, GF-1; and C, subunits of GF-1. Migration is towards the anode at the bottom. Gels A and B were run under nonreducing conditions and $\mathrm{Gel} \mathrm{C}$ under reducing conditions (8 M-urea). 


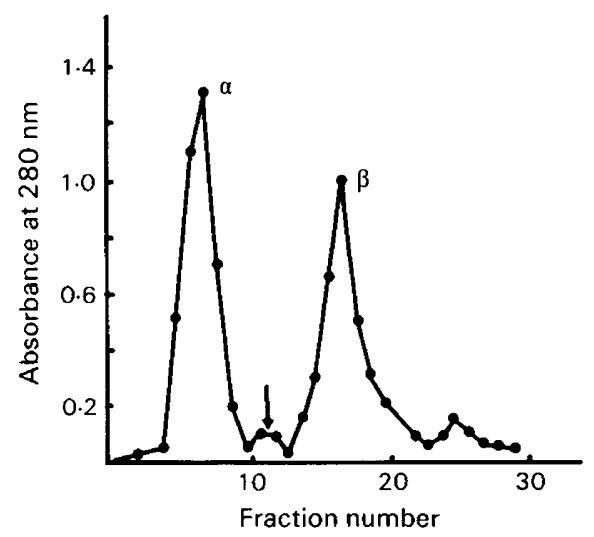

Text-fig. 2. Separation of the subunits of $400 \mathrm{mg}$ native GF-1 on DEAE-Sephadex A25. The arrow represents the application of the second buffer.

\section{Polyacrylamide gel electrophoresis}

Results for polyacrylamide gel electrophoresis are presented in Plate 1. The crude preparation of CPE-26 yielded 3 broad and 5 narrow bands and the purified preparation GF-1 yielded one broad band, and a smaller more slowly migrating band near the cathode. After elution most of the immunoassay potency was present in the larger band $(88 \% ; 210 \mathrm{mi} . \mathrm{u} . / \mathrm{ml})$ when compared to the smaller band $(12 \% ; 29 \mathrm{mi} . \mathrm{u} . / \mathrm{ml})$. Polyacrylamide gel electrophoresis run under reducing conditions ( $8 \mathrm{M}$-urea) gave two broad bands and smaller bands near the cathode.

\section{Discussion}

The value of 0.38 obtained for the absorbance of an aqueous solution $(1 \mathrm{mg} / \mathrm{ml})$ of the purified guinea-pig preparation (GF-1) compares well with the value of 0.388 reported for hCG (Bahl, 1969).

Purified hCG has been reported to give up to 6 bands on isoelectric focussing (Brossmer, Dorner, Hilgenfeldt, Leidenberger \& Trude, 1971; Graesslin, Weise \& Czygan, 1972; Merz, Hilgenfeldt, Dorner \& Brossmer, 1974; Qazi, Mukherjee, Javidi, Pala \& Diczfalusy, 1974) and similar results were obtained with the purified guinea-pig preparation (GF-1). Microheterogeneity in hCG is common as reflected by its behaviour in polyacrylamide gel, isoelectric focussing and ionexchange chromatography (Goverde, Veenkamp \& Homan, 1968; Van Hell, Matthijsen \& Homan, 1968; Bahl, 1969; Graesslin, Weise \& Braendle, 1973; Merz et al., 1974). All these forms have been shown to have an almost identical amino acid composition with variation in their carbohydrate portion, especially the sialic acid content (Bahl, 1973) and it has been suggested that this microheterogeneity could come from the introduction of artefacts during isolation or from the incomplete synthesis of carbohydrate chains. Consideration of the fact that all the 6 bands of GF-1 obtained by isoelectric focussing had an immunoassay potency suggests that the guinea-pig preparation, like the hCG, exhibits microheterogeneity.

Biological potencies of purified hCG have been reported to be between 12000 and 19000 i.u./mg (Bahl, 1969; Morgan \& Canfield, 1971; Pierce, Bahl, Cornell \& Swaminathan, 1971; Bahl, Carlsen \& Bellisario, 1973; Morgan, Canfield, Vaitukaitis \& Ross, 1974) and these are always higher than the immunological activities of highly purified hCG which are between 5600 and 7000 i.u./mg (Bahl, 1969; Donini, Oliveri, Ricci \& Donini, 1973). A similar situation was found when the guinea-pig preparation (GF-1) was used in these assays. 
The reported molecular weights for hCG calculated from gel filtration data are 83000 (Donini et al., 1973), 59000 (Bahl, 1969) and 67000 (Canfield, Morgan, Kammerman, Bell \& Agosto, 1971). The estimate of Bahl (1969) compares favourably with the results of the present study for GF-1. However, this method measured molecular dimensions and is known to give falsely high values for glycoproteins with appreciable carbohydrate content (Andrews, 1970). For this reason it was believed that the measure of Stokes' radius (a dimensional measure) would provide a more realistic estimate; the value of $3.40 \mathrm{~nm}(34 \AA)$ for GF-1 compared well with the value of $33 \AA$ reported for hCG (Mori, 1970). The values of Stokes' radii for the two subunits of GF-1 (23.8 $\AA$ and $31.5 \AA)$ are remarkably similar to the values of $23 \cdot 3 \AA$ and $30.2 \AA$ reported for the $\alpha$-and $\beta$-subunits by Morgan \& Canfield (1971).

Purified GF-1 run under non-reducing conditions gave a broad band and a small more slowly moving band near the cathode. Because this latter band was not observed in the electrophoretic pattern of the crude extract, but does have immunological activity, it is possible that this band was either too dilute to be detected in the original extract or had arisen as a consequence of purification procedures. It is known that the electrical charges of glycoproteins are affected by terminal sialic acid residues and this can affect the electrophoretic mobility. Thus these two bands may be due to two populations of GF-1 differing in their sialic acid content.

Morgan \& Canfield (1971) demonstrated the heterogeneity of the two hCG subunits by using polyacrylamide gel electrophoresis. They obtained two unequal broad bands and designated the broader, cathode-positioned band as the $\alpha$-subunit, and the smaller anode band as the $\beta$-subunit. Similar results were obtained with the guinea-pig preparation GF-1 and we were also able to obtain a $63 \%$ recombination of the $\alpha$ - and $\beta$-subunits.

In the results discussed above, it has been shown that the purified guinea-pig preparation (GF1) and hCG are similar in terms of their behaviour during ion-exchange chromatography, polyacrylamide gel electrophoresis and isoelectric focussing and they have similar Stokes' radii. Both have two non-covalently linked subunits, and display microheterogeneity. In addition to such similar physicochemical properties, GF-1 also possessed high biological activity in the rat ovarian ascorbic acid depletion assay and also a high immunological potency in the specific hCG- $\beta$ immunoassay.

We thank the Royal Commission for the Exhibition of 1851 and the Rutherford Memorial Committee of the Royal Society for financial support to C.S.B.

\section{References}

Allen, W.R. (1979) Maternal recognition of pregnancy and immunological implications of trophoblastendometrium interactions in equids. In Maternal Recognition of Pregnancy (Ciba Fdn Symp. No. 64), pp. 323-352. Excerpta Medica, Amsterdam.

Ambler, J. \& Walker, G. (1979) Isoelectric focussing of serum proteins on modified cellulose-acetate membranes. Clin. Chem. 25, 1320-1322.

Andrews, P. (1970) Estimation of molecular size and molecular weights of the biological compounds by gel-filtration. In Methods of Biochemical Analysis, Vol. 18, pp. 1-93. Ed. D. Glick. Interscience, New York.

Aschheim, S. \& Zondek, B. (1927) Ei und hormon, hypophysenvorderlappenhormon und Ovarialhormon im Harn von Schwangeren. Klin. Wschr. 6, 1322.

Bahl, O.P. (1969) Human chorionic gonadotropin. I. Purification and physicochemical properties. J. biol. Chem. 244, 567-574.
Bahl, O.P. (1973) Chemistry of human chorionic gonadotropin. In Hormonal Proteins and Peptides. pp. 171-199. Ed. C. H. Li. Academic Press, New York.

Bahl, O.P., Carlsen, R.B. \& Bellisario, R. (1973) Human chorionic gonadotrophin. Amino acid sequence of the $\alpha$ - and $\beta$-subunits and the nature and location of the carbohydrate units. Proc. 4th Int. Congr. Endocr., pp. 667-672. Eds R. O. Scow, F. G. J. Ebling \& I. W. Henderson. Excerpta Medica, Amsterdam.

Bambra, C.S. (1981) Placental gonadotrophins in the guinea-pig. Ph.D. thesis, University of Nottingham.

Brossmer, R., Dorner, M., Hilgenfeldt, U., Leidenberger, E. \& Trude, E. (1971) Purification and characterization of hCG. FEBS Letters 15, 33-37.

Canfield, R.E., Morgan, F.J., Kammerman, S., Bell, J.J. \& Agosto, G.M. (1971) Studies of human chorionic gonadotrophin. Recent Prog. Horm. Res. 27, 121-164.

Cole, H.H. \& Hart, G.H. (1930) The potency of blood serum of mares in progressive stages of pregnancy in 
affecting the sexual maturity of the immature rat. Am. J. Physiol. 93, 57-61.

Donini, S., Oliveri, G., Ricci, G. \& Donini, P. (1973) Subunits of human chorionic gonadotrophin: an immunochemical study. Acta endocr., Copenh. 73, 133-139.

Fishel, S.B. \& Surani, M.A.H. (1980) Evidence for the synthesis and release of a glycoprotein from mouse blastocysts. J. Reprod. Fert. 59, 181-187.

Gaddum, J.H. (1953) Simplified mathematics for bioassays. J. Pharm. Pharmac. 6, 345-358.

Gombe, S., Oduor-Okelo, D. \& Else, J. (1980) The potential of African mammals on new models for research in human reproduction. In Animal Models in Human Reproduction, pp. 345-358. Eds M. Serio \& L. Martini. Raven Press, New York.

Goverde, B.C., Veenkamp, F.J.N. \& Homan, J.D.H. (1968) Studies on human chorionic gonadotrophin. Acta endocr., Copenh. 59, $105-119$.

Graesslin, D., Weise, H.C. \& Czygan, P.J. (1972) Isolation and partial characterization of several different chorionic gonadotrophin (hCG) components. FEBS Letters 20, 87-89.

Graesslin, D., Weise, H.C. \& Braendle, W. (1973) The microheterogeneity of human chorionic gonadotrophin (hCG) reflected in the $\beta$-subunit. $F E B S$ Letters 31, 214-217.

Hobson, B. \& Wide, L. (1976) Relationship of the sex of the fetus to the amount of human chorionic gonadotrophin in placentae: single and dizygotic twin placentae compared. J. Endocr. 64, 117-123.

Hodgen, G.D., Tullner, W.W., Vaitukaitis, J.L., Ward, D.N. \& Ross, G.T. (1974) Specific radioimmunoassay of chorionic gonadotrophin during implantation in Rhesus monkeys. J. clin. Endocr. Metab. 39, 457-464.

Lee, C.Y., Wong, S., Lee, S.K. \& Ma, L. (1977) Purification and properties of chorionic gonadotrophin from human term placenta. Hoppe-Seyler's Z. Physiol. Chem. 358, 909-914.

Merz, W.E., Hilgenfeldt, V., Dorner, M. \& Brossmer, R. (1974) Biological, immunological and physical investigation on human chorionic gonadotrophin. Hoppe-Seyler's Z. Physiol. Chem. 355, 1035-1041.
Morgan, F.J. \& Canfield, R.E. (1971) Nature of the subunits of human chorionic gonadotropin. Endocrinology 88, 1045-1052.

Morgan, F.J., Canfield, R.E., Vaitukaitis, J.L. \& Ross, G.T. (1974) Properties of the subunits of human chorionic gonadotropin. Endocrinology 94, 16011608.

Mori, K.F. (1970) Antigenic structure of human chorionic gonadotropin: importance of protein moiety to the antigenic structure of human chorionic gonadotropin. Endocrinology 86, 97-106.

Parlow, A.F. (1961) Bioassay of pituitary luteinizing hormone by depletion of ovarian ascorbic acid. In Human Pituitary Gonadotropins, pp. 300-351. Ed. A. Albert. C. C. Thomas. Springfield.

Pierce, J.G., Bahl, O.P., Cornell, J.S. \& Swaminathan, N. (1971) Biologically active hormones prepared by recombination of the alpha chain of human chorionic gonadotrophin and the hormone-specific chain of bovine thyrotrophin or of bovine luteinizing hormone. J. biol. Chem. 246, 2321-2324.

Qazi, M.H., Mukherjee, G., Javidi, K., Pala, A. \& Diczfalsuzy, E. (1974) Preparations of highly purified human chorionic gonadotrophin by isoelectricfocussing. J. Biochem. 47, 219-229.

Ryan, R.J., Jiang, N.S. \& Hanlon, S. (1970) Some physical and hydrodynamic properties of human FSH and LH. Recent Prog. Horm. Res. 26, 105-137.

Swank, R.T. \& Munkres, K.D. (1971) Molecular weight analysis of oligopeptides by electrophoresis in polyacrylamide gel with sodium dodecyl sulfate. Analyt. Biochem. 39, 462-477.

Van Hell, H.R., Matthijsen, R. \& Homan, J.D.H. (1968) Studies on human chorionic gonadotrophin. I. Purification and some physicochemical properties. Acta endocr., Copenh. 59, 89-104.

Wide, L. \& Hobson, B. (1978) Chromatographic studies on a chorionic gonadotrophic activity in the placenta of the rat, mouse and hamster. Uppsala J. med. Sci. $83,1-6$.

Received 16 September 1983 